\title{
ESTUDO E MODELAGEM DA CINÉTICA DE DESIDRATAÇÃO OSMÓTICA DO MAMÃO FORMOSA (Carica papaya L.) ${ }^{1}$
}

\author{
Ânoar Abbas EL-AQUAR ${ }^{2, *}$, Fernanda E. Xidieh MURR ${ }^{2}$
}

\begin{abstract}
RESUMO
O presente trabalho teve como objetivo o estudo da cinética e modelagem do processo de desidratação osmótica de cubos de mamão Formosa (Carica papaya L.), assim como da qualidade do produto final. O tratamento osmótico foi conduzido a $30^{\circ} \mathrm{C}$, com agitação de $110 \mathrm{rpm}$, utilizando-se dois tipos de soluções de sacarose $70^{\circ}$ Brix: a primeira contendo lactato de sódio $2,4 \% \mathrm{p} / \mathrm{p}$ e ácido láctico $0,1 \mathrm{M}$ e a segunda com lactato de sódio $2,4 \% \mathrm{p} / \mathrm{p}$ e ácido cítrico $0,1 \mathrm{M}$. O estudo da cinética de desidratação osmótica mostrou que a solução contendo ácido cítrico apresentou valor de perda de água (WL), ao final de 48 horas de processo, ligeiramente superior ao encontrado para a solução contendo ácido láctico. Comportamento contrário ocorreu para o ganho de sólidos (SG). O ajuste dos dados experimentais foi realizado através do modelo difusional para geometria cúbica, sem considerar encolhimento durante o processo e um modelo empírico de dois parâmetros. Os coeficientes de difusividade efetiva de água $\left(\mathrm{D}_{\mathrm{ef}}\right)$ variaram de 1,27 a $5,03 \times 10^{-10} \mathrm{~m}^{2} / \mathrm{s}$. A qualidade da fruta após processamento foi avaliada através de análises de vitamina $\mathrm{C}$, carotenóides totais, acidez e pH.

Palavras-chave: mamão; desidratação osmótica; difusividade efetiva.
\end{abstract}

\section{SUMMARY}

KINETICS AND MODELING ON OSMOTIC DEHYDRATION OF PAPAYA (Carica papaya L.). The present work had as objective the study of kinetics and mathematical modeling of osmotic dehydration process of papaya cubes (Carica papaya L.), as well as the quality of the final product. The osmotic treatment was carried out for $30^{\circ} \mathrm{C}$, with agitation $110 \mathrm{rpm}$, with two types of $70^{\circ} \mathrm{Brix}$ sucrose solutions: solution containing sodium lactate $2,4 \% \mathrm{w} / \mathrm{w}$ and lactic acid $0,1 \mathrm{M}$ and another one with sodium lactate $2,4 \% \mathrm{w} / \mathrm{w}$ and citric acid $0,1 \mathrm{M}$. The study of kinetics of osmotic dehydration showed the solution containing citric acid had a water loss (WL) value, at the end of 48 hours of process, lightly superior to the found for the solution containing lactic acid. Opposite behavior happened for the solid gain (SG). Modeling of experimental data was accomplished through the difusional model for cubic geometry, considering no shrinkage during the process and an empirical two parameters one. The coefficients of effective difusivity of water $\left(D_{\text {ef }}\right)$ varied from 1,27 to $5,03 \mathrm{x}$ $10^{-10} \mathrm{~m}^{2} / \mathrm{s}$. Quality of fruit after processing was evaluated through vitamin C, total carotenoid, acidity and $\mathrm{pH}$ analyses.

Keywords: papaya; osmotic dehydration; effective difusivity.

\section{1 - INTRODUÇÃO}

Uma das principais causas da deterioração de alimentos frescos e também conservados é a quantidade de água livre presente nos mesmos [9]. Portanto, faz-se necessária a utilização de métodos ou combinação destes a fim de que o alimento se torne estável à deterioração química e microbiana [6]. O processo de desidratação osmótica é considerado um método capaz de obter um produto de boa qualidade mediante redução de sua umidade, sem mudança de fase durante o processo [7].

A desidratação osmótica é uma técnica bastante útil na concentração de frutas e vegetais, submetendo o alimento sólido, inteiro ou em pedaços, a soluções aquosas (sais ou açúcares) de alta pressão osmótica para que se verifique, de fato, a remoção da água não ligada presente no alimento. No caso de frutas, vêm sendo comumente usadas soluções de sacarose, com concentrações de 50 a $70^{\circ}$ Brix. [16].

Durante o processo de desidratação por osmose observam-se três tipos básicos de transferência de massa, ocorrendo simultaneamente: saída de água do produto para a solução hipertônica; saída de soluto da solução

1. Recebido para publicação em 23/05/2001. Aceito para publicação em 12/07/2002.

2. Universidade Estadual de Campinas - Depto. de Engenharia de Alimentos. Cx. Postal 6121, CEP 13083-970, Campinas-SP. E-mail: anoar@ceres.fea.unicamp.br

* A quem a correspondência deve ser enviada. para o produto. Através desta transferência é possivel se introduzir uma quantidade desejada de princípio ativo, agente conservante, qualquer outro soluto de interesse nutricional ou um capaz de conferir ao produto uma melhor qualidade sensorial; saída de alguns solutos do próprio produto (açúcares, ácidos orgânicos, sais minerais, vitaminas). Embora seja em quantidades desprezíveis, quando comparada aos dois itens anteriormente citados, exerce uma importante influência com relação à composição final do produto [14].

A taxa de perda de água durante a desidratação osmótica sofre a influência dos seguintes fatores: características do tecido vegetal, tipo e concentração do agente desidratante, temperatura, tempo de imersão, proporção fruta/solução e agitação [8].

Algumas das vantagens de se utilizar o processo de desidratação por osmose são a capacidade de conferir à fruta maior qualidade à sua textura, proporcionar uma maior retenção das vitaminas, intensificação do flavor e estabilidade na cor. Mediante este processo é possivel obter produtos de alta qualidade capazes de serem incorporados a produtos de padarias, confeitos ou a cereais prontos para consumo [4].

As frutas tropicais, como o mamão, por exemplo, são bastante conhecidas em todas as partes do mundo. As perdas de frutas em vários países em desenvolvimento ficam entre 10 e $40 \%$ devido à necessidade de uma melhor conservação [11]. 
De acordo com o exposto, pôde-se perceber a importância da utilização de novas técnicas para conservação de alimentos, principalmente, de frutas, as quais são altamente pereciveis. Sendo assim, o presente trabalho teve como objetivo estudar e modelar o processo de desidratação osmótica de cubos de mamão Formosa (Carica papaya L.), bem como avaliar a qualidade do produto final mediante análises de vitamina $\mathrm{C}$, carotenóides totais, acidez e $\mathrm{pH}$.

\section{2 - MATERIAL E MÉTODOS}

Foram utilizados mamões da variedade Formosa, observando-se critérios de grau de maturação (pela avaliação da textura e cor da casca), mesmo tamanho e forma com o objetivo de se padronizar a matéria-prima. Os mamões foram adquiridos no mercado local (CEASA de Campinas - SP). Os frutos foram descascados manualmente até a remoção completa da casca. As sementes foram removidas e a polpa foi cortada em cubos de aresta de $20 \mathrm{~mm}$ com o auxílio de um cortador construído em lâmina de alumínio, com base quadrada, sobre a qual foi acoplada uma haste de apoio para aplicação da força que promove o corte das amostras. A composição centesimal da fruta in natura foi determinada de acordo com RANGANNA [12]. Para a desidratação osmótica foram preparadas dois tipos de soluções de sacarose $70^{\circ}$ Brix; a primeira contendo lactato de sódio $2,4 \% \mathrm{p} / \mathrm{p}$ e ácido láctico $0,1 \mathrm{M}$ e a segunda com lactato de sódio $2,4 \% \mathrm{p} / \mathrm{p}$ e ácido cítrico $0,1 \mathrm{M}$. As soluções foram deixadas em repouso até sua estabilização (solução límpida, sem partículas suspensas). A concentração das soluções foi verificada por meio de um refratômetro. Os cubos de mamão, previamente pesados e identificados, foram colocados em frascos de aproximadamente $250 \mathrm{~mL}$, juntamente com a solução osmótica. As amostras foram levadas a uma incubadora, marca TECNAL, modelo TE-421, com controle de agitação $(110 \mathrm{rpm})$ e temperatura $\left(30^{\circ} \mathrm{C}\right)$. Foi utilizada uma proporção fruta:solução de 1:10, a fim de se garantir que a concentração da solução osmótica permanecesse constante ao longo do processo. As amostras foram retiradas em tempos de 15, 45, 90, 150, 240, $420,720,1440,2160,2880$ minutos, totalizando 48 horas de experimento, momento em que se obteve o equilíbrio para ambas as condições. As amostras, após serem retiradas da incubadora, foram lavadas com água destilada, para se remover o excesso de solução desidratante, drenadas e finalmente pesadas. Após terem sido pesadas, as amostras foram embaladas em papel filme e levadas a um dessecador para posterior análise de umidade. Todas as determinações foram feitas em triplicata.

\section{1 - Cinética de desidratação osmótica}

A cinética de desidratação foi estudada pelo acompanhamento da perda de água (WL) e ganho de sólidos (SG). A perda de água foi calculada pela Equação 1:

$W L(\%)=100 \frac{\left(E_{0}-E_{t}\right)}{M_{0}}$ onde:

$W L=$ perda percentual de água em relação à massa inicial;

$E_{0}=$ conteúdo inicial de água no produto $(\mathrm{g})$;

$E_{t}=$ conteúdo de água no produto a um tempo $\mathrm{t}(\mathrm{g})$

$M_{0}=$ massa inicial de produtos $(\mathrm{g})$.

Para o ganho de sólidos (SG), utilizou-se a Equação 2:

$S G(\%)=100 \frac{\left(m s_{t}-m s_{0}\right)}{M_{0}}$

Onde:

$S G$ = ganho percentual de sólidos em relação à massa inicial do produto;

$m s_{0}=$ matéria seca inicial $(\mathrm{g})$;

$m s_{t}=$ matéria seca em um tempo $\mathrm{t}(\mathrm{g})$;

$M_{0}=$ massa de produto no tempo inicial $(\mathrm{g})$.

\section{2 - Modelagem matemática}

Para estudar a cinética de desidratação osmótica, fazse uso da Teoria Difusional, a qual se baseia na equação da difusão líquida (Segunda Lei de Fick), onde o fluxo de massa é proporcional ao gradiente de concentração dentro do sólido. CRANK [3] propôs uma solução analítica para a Lei de Fick, considerando distribuição de umidade inicial uniforme e ausência de qualquer resistência térmica para uma placa plana infinita (Equação 3):

$\frac{X_{t}-X_{e}}{X_{0}-X_{e}}=\frac{8}{\pi^{2}} \sum_{i=0}^{\infty} \frac{1}{(2 i+1)^{2}} \exp \left[-(2 i+1)^{2} \pi^{2} D_{e f} \frac{t}{4 L^{2}}\right]$

Onde:

$X_{t}=$ umidade média no tempo $(\mathrm{t})$;

$X_{e}=$ umidade de equilíbrio;

$X_{O}=$ umidade inicial;

$D_{e f}=$ difusividade efetiva;

$t=$ tempo;

$L=$ dimensão característica (meia espessura da placa).

Partindo da Equação 3, pode-se obter uma equação para geometria cúbica. De acordo com TREYBAL [18], resolvendo a Lei de Fick para uma geometria retangular, ter-se-ia o produto de três termos adimensionais: $\left[\left(\mathrm{X}_{\mathrm{t}}-\right.\right.$ $\left.\left.\mathrm{X}_{\mathrm{e}}\right) /\left(\mathrm{X}_{0}-\mathrm{X}_{\mathrm{e}}\right)\right]_{\mathrm{a}}$, correspondente a uma meia espessura $\boldsymbol{a}$, $\left[\left(\mathrm{X}_{\mathrm{t}}-\mathrm{X}_{\mathrm{e}}\right) /\left(\mathrm{X}_{0}-\mathrm{X}_{\mathrm{e}}\right)\right]_{\mathrm{b}}$, para uma meia espessura $\boldsymbol{b}$ e $\left[\left(\mathrm{X}_{\mathrm{t}}-\right.\right.$ $\left.\left.\mathrm{X}_{\mathrm{e}}\right) /\left(\mathrm{X}_{0}-\mathrm{X}_{\mathrm{e}}\right)\right]_{\mathrm{c}}$, para uma meia espessura $\boldsymbol{c}$. No caso de um cubo, como $\boldsymbol{a}, \boldsymbol{b}$ e $\boldsymbol{c}$ são iguais, isso corresponderia à elevar a solução de Fick para placa plana infinita ao cubo, chegando-se à Equação 4:

$\left[\frac{X_{t}-X_{e}}{X_{0}-X_{e}}\right]_{\text {cubo }}=\left[\frac{8}{\pi^{2}} \sum_{i=0}^{\infty} \frac{1}{(2 i+1)^{2}} \exp \left[-(2 i+1)^{2} \pi^{2} D_{e f} \frac{t}{4 L^{2}}\right]\right]^{3}$

Onde a dimensão característica agora passa a ser a aresta do cubo $(2 L)$. 
A Equação 4 foi utilizada para os primeiros 15 termos da série, através dos dados de umidade determinados ao longo do processo.

Até o momento, as equações publicadas para a desidratação osmótica são bastante complexas e específicas para certas condições de processamento e configurações geométricas (placa, cilindro, esfera). AZUARA et al. [1] encontraram uma equação capaz de predizer a cinética de desidratação osmótica, bem como a determinação do ponto final de equilíbrio, sem a necessidade de se chegar, de fato, ao equilíbrio, utilizando apenas um curto período de processo. Partindo de um balanço de massa no material que sofre desidratação, chega-se a seguinte equação para a perda de água do produto $(W L)$ :

$W L=\frac{S_{1} t\left(W L_{\infty}\right)}{1+S_{1} t}$

Os valores de $S_{1}$ (constante relacionada à perda de água) e $W L_{z}$ (situação de equilíbrio) podem ser encontrados a partir da linearização da Equação 5:

$$
\frac{t}{W L}=\frac{1}{S_{1}(W L \infty)}+\frac{t}{W L \infty}
$$

O modelo pode ser usado para caracterizar a desidratação osmótica de diferentes tipos de alimentos, sem restrições de geometria.

CRANK [3], baseado na Segunda Lei de Fick para uma placa plana em contato com uma quantidade infinita de solução, considerando regime transiente e curtos períodos de tempo, chegou a uma equação simplificada do tipo:

$\frac{W L_{t}}{W L \infty}=2\left(\frac{D_{e f}}{\pi L^{2}}\right)^{1 / 2}$

Onde:

$W L_{t}=$ quantidade de água deixando o sólido no tempo t; $W L ¥=$ quantidade de água deixando o sólido depois de um tempo infinito;

Baseados nas Equações 5 e 7, AZUARA et al. [1] obtiveram uma equação capaz de calcular a difusividade efetiva para a perda de água, considerando uma geometria similar a uma placa plana infinita (Equação 8):

$D_{e f}=\frac{\pi t}{4}\left[\left(\frac{S_{1} L}{1+S_{1} t}\right)\left(\frac{W L_{\infty}^{\mathrm{mod}}}{W L_{\infty}^{\mathrm{exp}}}\right)\right]^{2}$

Onde:

$W L_{\infty}^{\text {mod }}=$ valor no equilíbrio obtido pela Equação 5;

$W L_{\infty}^{\text {exp }} \quad$ = valor no equilíbrio obtido experimentalmente;

Rearranjando a Equação 7 para uma geometria cúbica, isto é, considerando a dimensão característica como sendo a aresta do cubo, e substituindo-a à Equação 5, chegamos à Equação 9:
$D_{e f}=\frac{\pi}{4 t^{1 / 3}}\left[\left(\frac{S_{1} L^{3}}{1+S_{1} t}\right)\left(\frac{W L_{\infty}^{\bmod }}{W L_{\infty}^{\exp }}\right)\right]^{2 / 3}$

A difusividade referente ao processo é calculada fazendo-se uma média aritmética dos valores de difusividade encontrados para cada tempo (Equação 10):

$\overline{D_{e f}}=\frac{\sum_{i=1}^{\infty} D_{e f(i)}}{N}$

Onde:

$\overline{D_{e f}}=$ difusividade efetiva média;

$D_{\text {efi }}=$ difusividades efetivas para cada tempo;

$N$ = número de pontos experimentais utilizados para o cálculo.

$\mathrm{O}$ erro relativo médio $(\mathrm{P})$ foi calculado através da Equação 11 a fim de avaliar se os modelos utilizados foram ou não preditivos $(\mathrm{P}<10 \%)$.

$P=\frac{100}{N} \sum_{i=1}^{N} \frac{\left|V_{P}-V_{O}\right|}{V_{O}}$

Onde:

$P=$ desvio relativo médio (\%);

$V_{P}=$ valores preditos pelo modelo;

$V_{O}=$ valores observados experimentalmente;

$N=$ número de pontos experimentais.

\section{3 - Qualidade do produto final}

A qualidade do produto final foi avaliada por meio de análises de vitamina $\mathrm{C}$, carotenóides totais, acidez e $\mathrm{pH}$ para 4 horas de processo, periodo em que foram observadas as maiores taxas de remoção de água.

\section{3 - RESULTADOS E DISCUSSÕES}

\section{1 - Composição centesimal da fruta}

A Tabela 1 mostra a caracterização físico-química do mamão Formosa in natura:

TABELA 1. Caracterização físico-química da fruta in natura.

\begin{tabular}{lc}
\hline \multicolumn{1}{c}{ Análise } & Valor médio \\
\hline Conteúdo de umidade $\left(\mathrm{bu}^{*}-\%\right)$ & 87,73 \\
Acidez $(\%$ ácido cítrico) & 0,12 \\
Açúcares redutores $(\%)$ & 10,16 \\
Açúcares totais $(\%)$ & 10,19 \\
Carotenóides totais $(\mu \mathrm{g} / \mathrm{g})$ & 37,02 \\
Vitamina C $(\mathrm{mg} / 100 \mathrm{~g}$ produto) & 71,31 \\
PH & 5,75 \\
\hline
\end{tabular}

*base úmida.

Comparando os resultados da Tabela 1 aos obtidos por MENEZES et al. [10], observa-se que o conteúdo de umida- 
de é ligeiramente inferior ao da literatura. O mesmo não acontece com a acidez, açúcares redutores e totais, os quais apresentam valores um pouco superiores aos encontrados pela literatura. O teor de vitamina $\mathrm{C}$ encontra-se na faixa de 30 - 130mg / $100 \mathrm{~g}$ de produto. A quantidade de carotenóides totais está na faixa de $27,8-37,8 \mu \mathrm{g} / \mathrm{g}$ obtida por KIMURA, RODRIGUEZ-AMAYA, YOKOYAMA [5].

\section{2 - Cinética de desidratação osmótica}

A Figura 1 mostra dados da perda de água para as duas soluções estudadas, durante 48 horas de processo. Observa-se uma perda de água ao final da desidratação de aproximadamente $80 \%$ para ambas as soluções. A perda de água ocorre mais intensamente nas quatro primeiras horas, como afirma LENART [7], alcançando um valor de aproximadamente $45 \%$, ou seja, mais que a metade do valor alcançado no equilíbrio. Este comportamento também foi observado por SANJINÉZ-ARGADOÑA [15] trabalhando com goiaba.

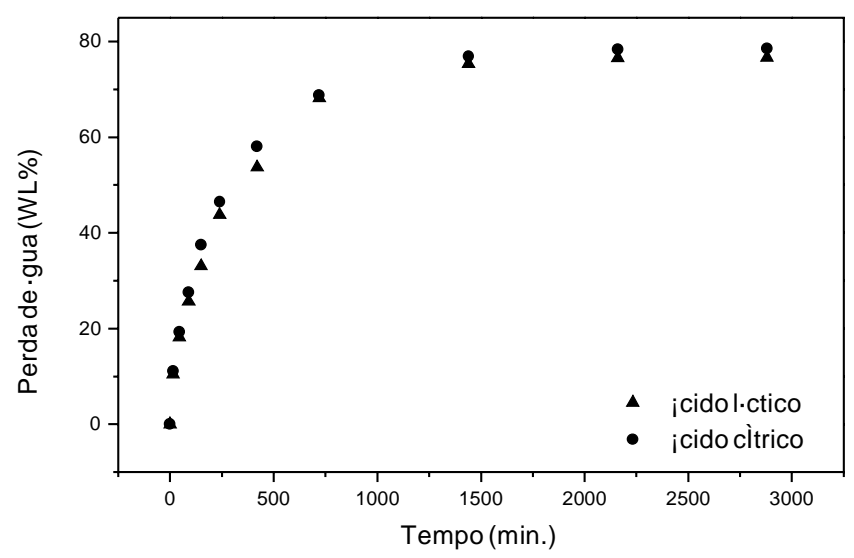

FIGURA 1. Perda de água em função do tempo para as soluções osmóticas com ácido láctico e cítrico.

Assim também, a Figura 2 mostra o ganho de sólidos durante 48 horas de processo. O ganho de sólidos aconteceu mais intensamente na primeira hora do processo, chegando ao equilibrio pouco tempo depois, como também foi observado por RAOULT-WACK, LENART, GUILBERT [13].

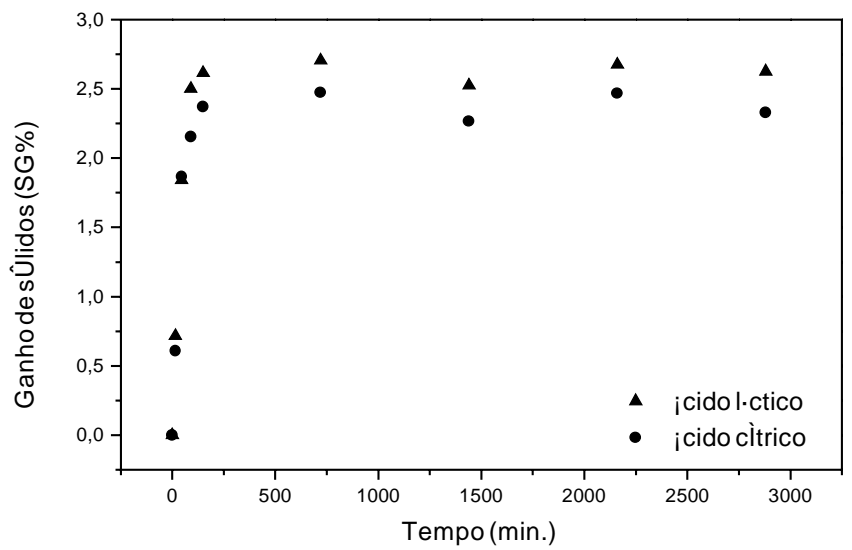

FIGURA 2. Ganho de sólidos em função do tempo para as soluções osmóticas com ácido láctico e cítrico.
Observa-se que o fluxo de perda de água é bem maior que o de ganho de sólidos. Para o presente estudo, este fato é extremamente importante, uma vez que se deseja preservar ao máximo as características da fruta in natura, incorporando menos sólidos.

As Figuras 3 e 4 mostram, respectivamente o termo adimensional de umidade e taxa de desidratação em função do tempo para ambas as soluções osmóticas.

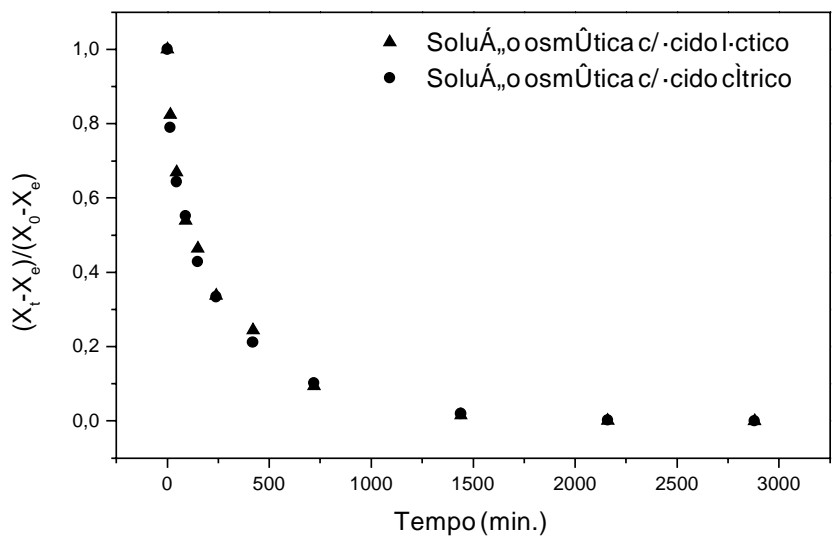

FIGURA 3. Termo adimensional de umidade em função do tempo para ambas as soluções osmóticas.

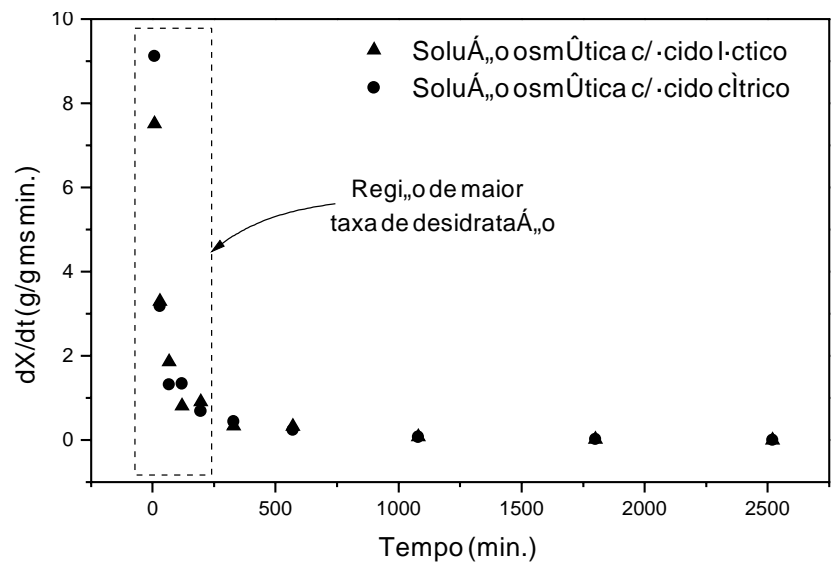

FIGURA 4. Taxa de desidratação osmótica em função do tempo para ambas as soluções osmóticas.

Para a perda de água, as duas soluções apresentaram comportamento muito semelhante. Em relação ao ganho de sólidos, a solução contendo ácido láctico obteve um ganho ligeiramente superior.

É importante salientar que o peso molecular do ácido láctico é de 90,08g/gmol enquanto que o do ácido cítrico é de 192,13g/gmol, ou seja, mais que o dobro da massa molar do ácido láctico. De acordo com TORREGGIANI [16], o aumento do peso molecular do agente osmótico provoca uma diminuição no ganho de sólidos e um aumento na perda de água, favorecendo com isso a perda de peso.

$\mathrm{O}$ fato é que a sacarose parece reger o processo de transferência de massa, uma vez que se encontra em maior quantidade na solução. Embora de maneira dis- 
creta, a influência do tipo de ácido se faz presente, confirmando a afirmação feita anteriormente, ou seja, mesmo estando em menor proporção, a presença dos ácidos é capaz de contribuir na massa molar global da solução osmótica, afetando com isso o processo de transferência de massa.

Observando-se a Figura 4, foi escolhido um tempo de 4 horas de processo como sendo o ideal para se proceder as análises do produto final. Percebe-se nitidamente que a maior taxa de transferência de massa ocorreu neste período.

\section{3 - Modelagem matemática}

Em relação à modelagem matemática dos dados de cinética de desidratação osmótica, a Figura 5 mostra o ajuste feito com o modelo difusional sem considerar encolhimento para ambas as soluções osmóticas.
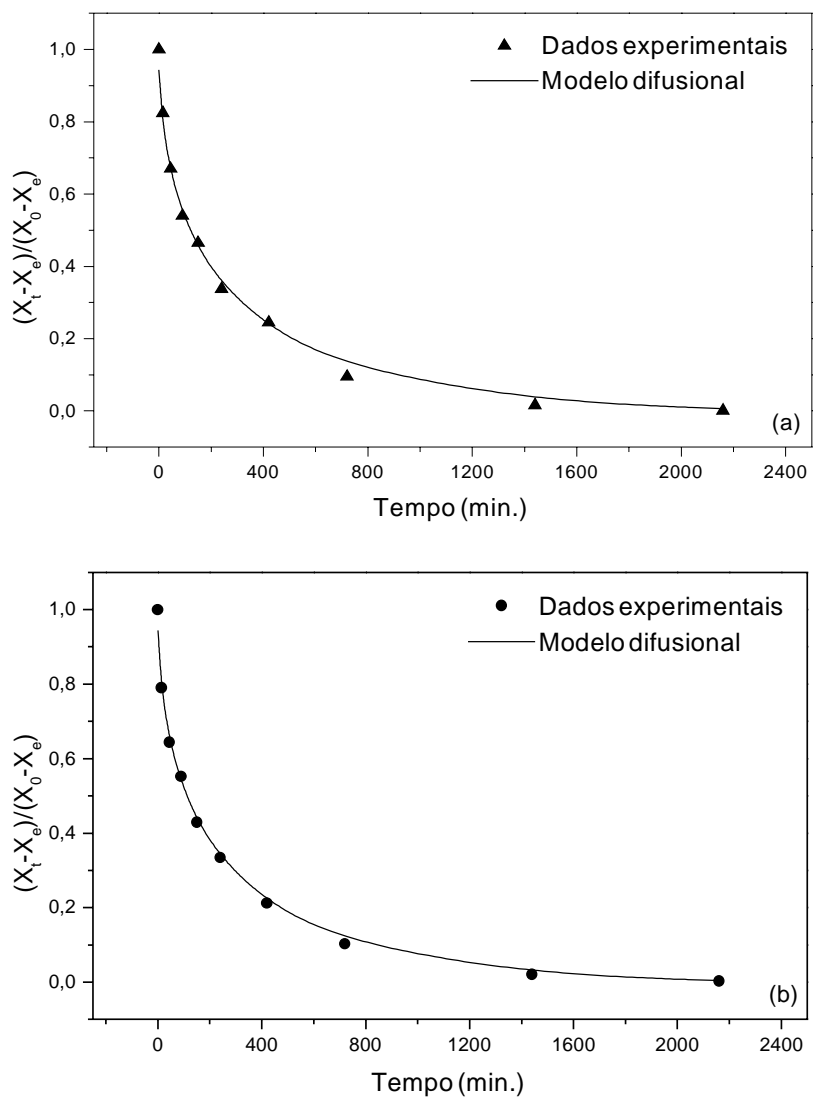

FIGURA 5. Ajuste feito pelo modelo difusional sem considerar encolhimento para os dados de cinética da desidratação osmótica da solução contendo ácido láctico (a) e cítrico (b).

A Tabela 2 mostra os valores obtidos para a difusividade efetiva $\left(D_{e f}\right)$, coeficiente de correlação $\left(R^{2}\right)$ e erro relativo médio $(\mathrm{P})$ para ambas as soluções osmóticas.

De acordo com a Tabela 2 observa-se que o valor da difusividade efetiva foi um pouco superior para a solução contendo ácido cítrico, uma vez que esta apresentou uma perda de água ligeiramente maior.
TABELA 2. Valores de $D_{\text {ef }}, R^{2}$ e $P$ para o modelo difusional sem encolhimento.

\begin{tabular}{cccc}
\hline Amostra & $\mathbf{D}_{\text {ef }} \mathbf{x} \mathbf{1 0}^{\mathbf{1 0}}\left(\mathbf{m}^{2} / \mathbf{s}\right)$ & $\mathbf{R}^{2}$ & $\mathbf{P}(\boldsymbol{\%})$ \\
\hline Solução c/ ácido láctico & & & \\
Solução c/ ácido cítrico & 4,66 & 0,9943 & 18,12 \\
& 5,03 & 0,9965 & 7,55
\end{tabular}

O modelo difusional, para os primeiros 15 termos da série, sem considerar encolhimento, foi capaz de predizer a cinética de desidratação osmótica de maneira satisfatória apenas para a condição de desidratação contendo ácido cítrico, apresentando valor de erro relativo médio plausivel (até $10 \%$ ). Tal fato pode ter ocorrido por não se ter considerado encolhimento durante o processo.

As Figuras 6 e 7 mostram os dados de cinética e as linearizações necessárias ao modelo proposto por AZUARA et al. [1], para quatro horas de processo para ambas as soluções osmóticas.
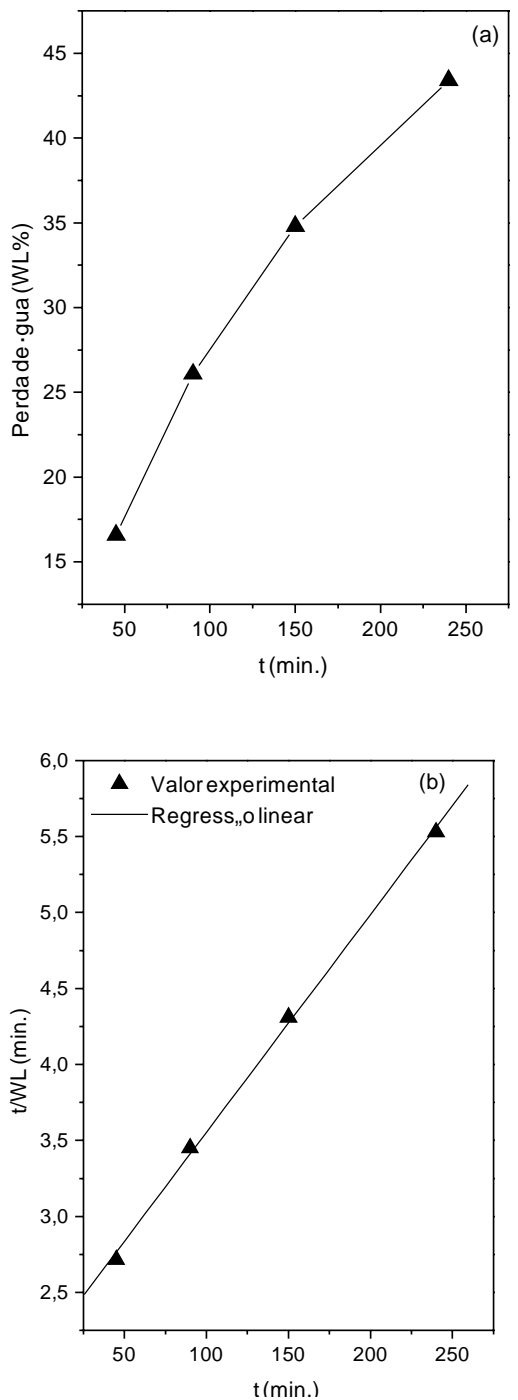

FIGURA 6. Solução osmótica contendo ácido láctico. (a) Perda de água em função do tempo p/ 4 horas de processo; (b) Modelo. 

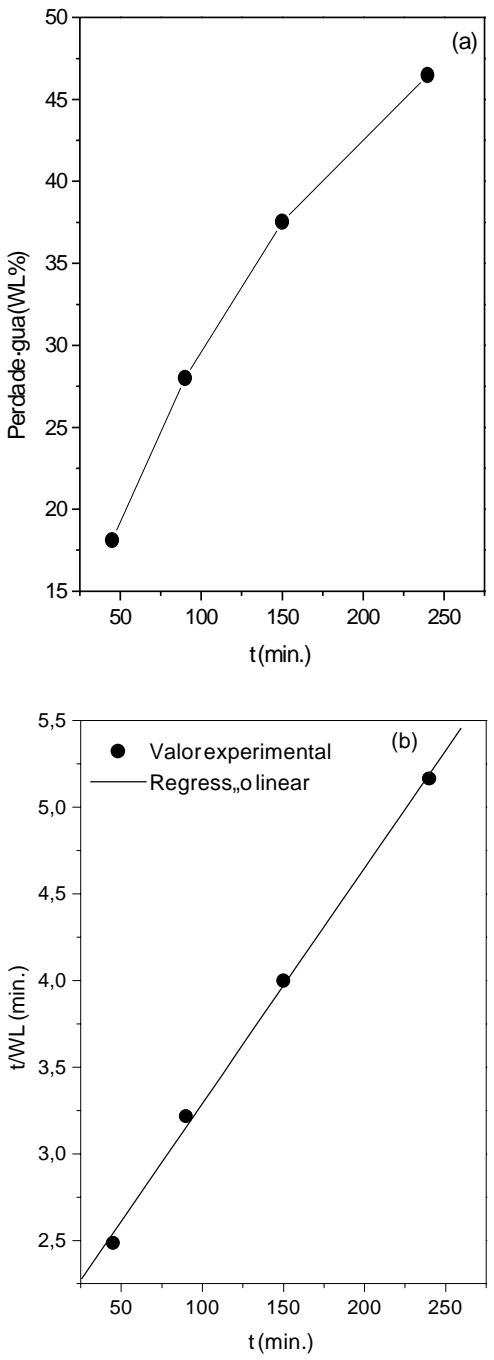

FIGURA 7. Solução osmótica contendo ácido cítrico. (a) Perda de água em função do tempo p/ 4 horas de processo; (b) Modelo.

A Tabela 3 mostra os valores obtidos para o parâmetro $\left(\mathrm{S}_{1}\right)$, perda de água no equilíbrio $\left(W L_{\infty}^{\mathrm{mod}}\right)$ predita pelo modelo e encontrada experimentalmente ( $\left.W L_{\infty}^{\exp }\right)$, difusividade efetiva $\left(D_{e f}\right)$, coeficiente de regressão $\left(R^{2}\right)$ e erro relativo médio $\left(\mathrm{P}\right.$ e $\left.\mathrm{P}^{\prime}\right)$.

TABELA 3. Valores de ajuste e predição do modelo de AZUARA et al.

\begin{tabular}{cccccccc}
\hline Amostra & $\mathbf{S}_{\mathbf{1}} \mathbf{x} \mathbf{1 0}^{3}$ & $W L_{\infty}^{\mathrm{mod}}(\boldsymbol{\%})$ & $W L_{\infty}^{\mathrm{exp}}(\boldsymbol{\%})$ & $\begin{array}{c}\mathbf{P} * \\
(\boldsymbol{\%})\end{array}$ & $\begin{array}{c}\mathbf{D}_{\mathrm{ef}} \mathbf{x} \mathbf{1 0} \\
\left(\mathbf{m}^{2} / \mathbf{s}\right)\end{array}$ & $\mathbf{R}^{\mathbf{1 0}}$ & $\mathbf{P}(\boldsymbol{\%})$ \\
\hline Sol. c/ Ác. Láctico & 6,70 & 69,93 & 76,31 & 8,36 & 1,27 & 0,9985 & 1,13 \\
Sol. c/ Ác. Cítrico & 7,00 & 73,53 & 78,49 & 6,32 & 1,31 & 0,9977 & 1,40 \\
\hline
\end{tabular}

* erro relativo médio referente à perda de água no equilíbrio.

De acordo com a Tabela 3, observa-se o mesmo comportamento ocorrido na Tabela 2 para a difusividade efetiva. O modelo de AZUARA et al. [1] mostrou-se bastante preditivo para obtenção dos valores de perda de água no equilíbrio, apresentando valores de erro relativo médio
(P') e (P) aceitáveis. Já para o cálculo da difusividade efetiva, apresentou diferença significativa quando comparado aos valores obtidos pelo modelo difusional.

\section{4 - Qualidade do produto final}

A Tabela 4 mostra os resultados obtidos para as análises de vitamina $\mathrm{C}$, carotenóides totais, acidez e $\mathrm{pH}$ para 4 horas de processamento.

TABELA 4. Análises de vitamina $\mathrm{C}$, carotenóides, acidez e pH para ambas as condições de desidratação osmótica após 4 horas de processamento.

\begin{tabular}{lcccc}
\hline $\begin{array}{c}\text { Condição de desidratação } \\
\text { osmótica }\end{array}$ & $\begin{array}{c}\text { Vitamina C } \\
\left(\mathbf{m g} / \mathbf{1 0 0 g} \mathbf{~ m} \mathbf{s}^{*}\right)\end{array}$ & $\begin{array}{c}\text { Carotenóides } \\
\left(\mathbf{m g} / \mathbf{1 0 0 g} \mathbf{~ m s}^{*}\right)\end{array}$ & $\begin{array}{c}\text { Acidez } \\
(\% \text { de ácido cítrico) }\end{array}$ & $\mathbf{p H}$ \\
\hline in natura & 581,17 & 30,17 & 0,12 & 5,75 \\
Solução contendo ácido láctico & 558,54 & 29,67 & 0,70 & 3,57 \\
Solução contendo ácido cítrico & 561,17 & 29,41 & 1,02 & 3,06 \\
\hline * ms & & & &
\end{tabular}

${ }^{*} \mathrm{~ms}=$ matéria seca.

De acordo com a Tabela 4 percebe-se que as perdas de vitamina $\mathrm{C}$ e carotenóides foram mínimas para ambas as condições. Tal fato pode ter ocorrido devido à introdução de aditivos (ácidos cítrico e láctico; lactato e sódio) nas soluções osmóticas, prevenindo com isso a degradação por oxidação. Segundo CALIL, AGUIAR [2], tais aditivos são comumente utilizados na indústria de alimentos pelo seu alto poder antioxidante, retendo a vitamina $\mathrm{C}$ e prevenindo a descoloração da fruta.

Com relação à acidez, nota-se que apesar de os ácidos estarem na mesma concentração $(0,1 \mathrm{M})$ na solução osmótica, apresentaram valores distintos. Tal fato provavelmente se deve à natureza dos ácidos. O ácido láctico é um mono ácido enquanto que o cítrico é um tri ácido. Isto implica dizer que o caráter ácido para o cítrico é maior que o do láctico, o que pode explicar os valores obtidos. Como um dos objetivos deste trabalho é o de conservar ao máximo as características naturais da fruta, a melhor condição para consumo foi a contendo ácido láctico, uma vez que apresentou valor de acidez mais próximo da fruta in natura.

Pela Tabela 4, a fruta desidratada com ácido cítrico mostrou-se mais ácida. TORREZAN [17] afirma que o limite de crescimento de microrganismos varia numa faixa ampla que vai de $\mathrm{pH} 1$ a 11 . Muitos microrganismos têm o seu $\mathrm{pH}$ ótimo perto da neutralidade e crescem entre pH 5,4 e 6,3. Por exemplo, as bactérias acéticas possuem pH ótimo entre 5,4 e 6,3 e as lácticas entre 5,5 e 6,0. Para alimentos, a principal linha de demarcação de $\mathrm{pH}$ é o valor de 4,5. Observando os valores obtidos, chega-se à conclusão de que, para ambas as condições, os valores encontram-se abaixo deste limite. Considerando que a característica sensorial do mamão, com relação ao sabor, é de fruta não-ácida, a condição mais adequada para a sua desidratação osmótica foi a contendo ácido láctico.

\section{4 - CONCLUSÕES}

- Os resultados obtidos para a desidratação osmótica do mamão Formosa mostraram que a perda de água, 
ao final do processo, foi de aproximadamente $80 \%$, para ambas as condições, e ocorreu mais intensamente nas quatro primeiras horas de desidratação, momento em que já se havia perdido $45 \%$ do conteúdo de água inicial, isto é, mais da metade do valor alcançado no equilíbrio. A solução desidratante contendo ácido cítrico apresentou maior perda de água que a contendo ácido láctico. Comportamento contrário aconteceu com o ganho de sólidos.

- O modelo difusional para geometria cúbica, utilizando os 15 primeiros termos da série, sem considerar encolhimento, mostrou um bom ajuste apenas para a condição de desidratação contendo ácido cítrico. O modelo empírico apresentou um excelente ajuste, com valores de erro relativo médio inferiores a $2 \%$.

- Os valores de difusividade efetiva de água encontrados pelo modelo difusional para as condições contendo ácido láctico e cítrico foram 4,66 e 5,03 x $10^{-10} \mathrm{~m}^{2} / \mathrm{s}$, respectivamente.

- Através dos dados de cinética e análises de vitamina $\mathrm{C}$, carotenóides totais, acidez e $\mathrm{pH}$ foi escolhida a condição de desidratação contendo ácido láctico capaz de melhor preservar as características da fruta fresca.

\section{5 - REFERÊNCIAS}

[1] AZUARA, E.; CORTÉS, R.; GARCIA, H. S.; BERISTAIN, C. I. Kinetic model for osmotic dehydration and its relationship with Fick's second law. International Journal of Food Science and Technology, n. 27, p. $409-418,1992$.

[2] CALIL, R. M. \& AGUIAR, J. A. Aditivos nos Alimentos. 139p., São Paulo - SP, 1999.

[3] CRANK, J. The Mathematics of Diffusion, $2^{\mathrm{a}}$ ed. S.I Claredon Press Oxford, 414p., 1975.

[4] KARATHANOS, V. T. \& HOSTAROPOUlOS, A. E. Air-drying kinetics of osmotically dehydrated fruits. Drying Technology. v.13, n. 5-7, p. 1503 - 1521, 1995.

[5] KIMURA, M.; RODRIGUEZ-AMAYA, D. B.; YOKOYAMA, S. $M$. Cultivar differences and geographic effects on the carotenoid composition and vitamin A value of papaya. Lebensmittel-Wissenchaft und-Technologie. v. 24, p. 415 - 418, 1991.

[6] LABUZA, T. P. The effect of water activity on reaction kinetics of food deterioration. Food Technology, abril, p. 36 41,1980 .
[7] LENART, A. Osmo-convective drying of fruits and vegetables: Technology and application. Drying Technology, v. 14, n. 2, p. $391-413,1996$.

[8] LERICI, C. R.; PINNAVAIA, G.; DAlla ROSA, M.; BARTOLUCCI, L. Osmotic dehydration of fruit: Influence of osmotic agents on drying behavior and product quality. Journal of Food Science, v. 50, p. 1217 - 1226, 1985.

[9] MANNHEIM, C. H.; LIU, J. X.; GILBERT, S. G. Control of water in foods during storage. Journal of Food Engineering, n. 22, p. 509 - 532, 1994.

[10] MENEZES, H. C.; DRAETTA, I. S.; SALES, A. M.; LEITÃO, M. F. F.; CAMPOS, S. D. S.; CABRAL, A. C. D.; ORTIZ, S. A.; MADI, L. F. C.; SOLER, R. M.; GAZETA, E. F. Alguns Aspectos Tecnológicos das Frutas Tropicais e Seus Produtos, p. 46 - 50, 1980.

[11] PALOU, E.; LÓPEZ-MALO, A.; ARGAIZ, A.; WELTI, J. Osmotic dehydration of papaya. Effect of syrup concentration. Revista Española de Ciencia y Tecnologia de Alimentos, v. 33, n. 6, p. 621 - 630, 1993.

[12] RANGANNA, S. Manual of Analysis of Fruit and Vegetables Products. New Delhi: Mc - Graw Hill Publishing Company, 634p., 1977.

[13] RAOULT-WACK, A. L.; LENART, A.; GUILBERT S. Recent advances in dewatering though immersion in concentraded solutions. In: Drying of Solids. ed. A. S. Mujundar. International Science Publishers, New York, p. 211-51, 1992.

[14] RAOULT-WACK, A. L.; LENART, A.; GUILBERT, S. Recent advances in the osmotic dehydration of foods. Trends in Food Science \& Technology, v. 5, agosto, p. 225 260, 1994.

[15] SANJINÉZ-ARGADOÑA, E. J. Desidratação osmótica de goiaba por imersão e secagem. Campinas, 1999. 102 p. Dissertação (Mestre em Engenharia de Alimentos) Faculdade de Engenharia de Alimentos, Universidade Estadual de Campinas (UNICAMP).

[16] TORREGGIANI, D. Osmotic dehydration in fruit and vegetable processing. Food Research International, v. 26, p. $59-68,1993$.

[17] TORREZAN, R. Preservação de polpa de goiaba por métodos combinados. Campinas, 1996, 211p. Dissertação (Mestre em Tecnologia de Alimentos) - Faculdade de Engenharia de Alimentos, Universidade Estadual de Campinas.

[18] TREYBAL, R. E. Drying. In: Mass Transfer Operations. New York, McGraw-Hill, p. 569 - 575, 1963.

\section{6 - AGRADECIMENTOS}

Os autores agradecem pelo valioso apoio financeiro dado pela FAPESP, sem o qual não seria possível a realização deste trabalho. 